\title{
Evaluation of In-Vitro and In-Vivo Anticoagulant Activity of Orange Peel Extract
}

\section{Tera Sandhya* and Pasumarthy Sree Mahalakshmi}

Department of Pharmacology, Institute of Pharmaceutical Technology, Sri Padmavathi Mahila Viswavidyalayam, Tirupathi, India

*Corresponding Author: Tera Sandhya, Department of Pharmacology, Institute of Pharmaceutical Technology, Sri Padmavathi Mahila Viswavidyalayam, Tirupathi, India.
Received: September 18, 2020

Published: September 21, 2020

(C) All rights are reserved by Tera Sandhya

and Pasumarthy Sree Mahalakshmi.

\begin{abstract}
It is a common and necessary procedure that assist avert loss of life yet from slight damages by means of creating clumps or clots in an effort to discontinue bleeding from an injured or damaged vessel. The results acquired from this exploration advocate that the medicinal plant, Orange peel, possesses the capability to inhibit the aggregation of platelets: The extract of the plant peel inhibited the effect of thrombin on the artificial substrate (i.e. chromogenix), and subsequent too inhibited rat aggregation of platelets provoked with ADP, thrombin, and epinephrine. The anti-aggregation of Platelet effectiveness was seen mostly in the extract of the semipolar solvent extract highest dose indicating the highest effect. The capability of the extract to inhibit the arachidonic acid provoked aggregation of Platelet signify its potential to be developed into an excellent pharmacological anti-platelet and anti-inflammatory medicament.
\end{abstract}

Keywords: Anticoagulant Activity; Orange Peel Extract; Platelet Aggregation

\section{Introduction}

Orange is the world's most popular fruit. Citrus plants derived from the members of the Citrus family, orange often refers to the most popular Citrus sinensis and Citrus aurantium. Orange tree grows in tropical, semitropical, and warm temperate regions, becoming the most widely cultivated fruit tree in the world.

Citrus aurantium EO, also known as neroli oil, is widely used in aromatherapy. It is a strongly scented bitter liquid, produced by hydro distillation of Citrus aurantium fresh lives. Citrus aurantium L., named orange or sweet orange, is a millennial small tree belonging to the Rutaceae (Citrus) family originated in southern China. The orange tree is small, spiny tree, typically growing to $7.5 \mathrm{~m}$, but occasionally reaching heightsupto $15 \mathrm{~m}$, generally with a compact crown.
This plant is used to treat several health problems such as gastrointestinal disturbances, respiratory disorders, insomnia, stress disorders, epilepsy, and anxiety. Other Citrus species such as Citrus bergamia have been described for their effects against stress, psoriasis and hyperlipidaemia. Citrus aurantium L., also called Seville orange, sour orange, or bitter orange, is a small Citrus tree, about five meters tall, with scented white flowers, belonging to Rutaceae family, originating in eastern Africa, Arabia, and Syria, and cultivated in Spain, Italy and North America.

Citrus aurantium is called with several local common names in different countries where it is used for food, fragrance, and medical application. Fruit, peel, leaves, flowers, seeds and essential oil (EO) of Citrus aurantium are used in perfumes and cosmetics, as well as in the food and confectionery industry. Bitter orange oil, obtained 
from the pressure of the fresh peels, is widely used as a flavouring agent in the food industry and for beverages, particularly liquor and soft drink.

Flavones, alkaloids such as synephrine and octopamine, carotenoids, and N-methyltyramine are contained in peel, besides the volatile oil. The main active ingredient in bitter orange extract is the phenyl-ethylamine proto alkaloid p-synephrine which represents about $90 \%$ or more of the total proto alkaloids.

Fruit peel contains a volatile oil composed of d-limonene, d-linalool, $\mathrm{N}$-acetyl octopamine, gamma-aminobutyric acid, flavonoids, coumarin, triterpenes, vitamin-C, carotene and pectin. Other minor proto alkaloidal constituents in Citrus aurantium octopamine, hordenine, tyramine, and N-methyltyramine are absent or in trace amounts in bitter orange extracts. Standardized aqueous-alcoholic extracts of the immature fruits of Citrus aurantium are widely consumed in dietary supplements for appetite control, weight management, sports performance, and energy and bitter orange products are also consumed in the form of food as juices and marmalades.

Citrus aurantium contains several active secondary metabolites contributing to the pharmacological activities of the plant. In Citrus aurantium fruits, peel, leaves, juice, and roots, several types of chemical compounds including flavonoids, hydroxyamides, steroids, alkanes and fatty acids, coumarin, carbohydrates, peptides, carbamates and alkylamines, carotenoids, volatile compounds, and minerals such as potassium, magnesium, calcium, and sodium have been identified. C. sinensis is a rich source of vitamin $C$, a natural antioxidant that supports the immune system activity.

\section{Plant profile}

- $\quad$ Citrus aurantium

- Synonyms: Citrus sinensis

- Family: Rutaceae

- Common Names: Orange

(Figure A)

- Scientific classification (Table A)

\section{Vernacular names}

- Sanskrit: Brihatjambhira

- Hindi: Khatta

- Urdu: Nagorongo

- Telugu: Mallikanarangi

- Tamil: Narangam, Naratta.

\begin{tabular}{|l|}
\hline Kingdom: Plantae-Plants \\
\hline Subkingdom: Tracheobionta-Vascular plants \\
\hline Superdivision: Spermatophyta-Seed plants \\
\hline Division: Magnoliophyta-Flowering plants \\
\hline Class: Dicotyledonae \\
\hline Subclass: Rosidae \\
\hline Order: Sapindales \\
\hline Family: Rutaceae \\
\hline Genus: Citrus \\
\hline Species: sinensis \\
\hline
\end{tabular}

Table A

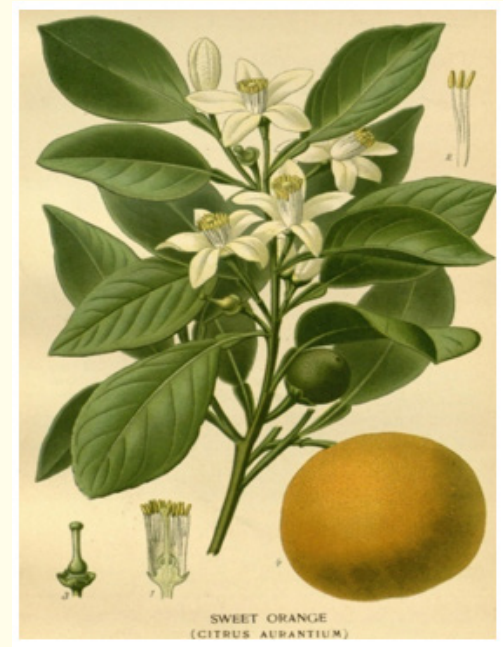

Figure A 


\section{Food uses}

Nowadays it may perhaps be established literally each and every one around the globe.

The orange is currently the most far and wide cultivated crop on earth. There are 3 foremost profit-making varieties:

1. Blood oranges,

2. Novel oranges and

3. Normal oranges even though loads of more are definitely grown in little quantities.

Blood oranges, widely known in Europe, contain orange skin although a flesh in deep red colour.

Normal oranges, counting the Valencia orange the majority generally grown in Florida, are the most widespread type utilized for orange juice.

Navel oranges are the most recent type in commercial cultivation, popular in California. The fruit of this type in fact contains a tiny orange (the navel) at the tip along with its bigger additional edible complement. The fruit is approximately always seedless, so every one of novel fruit trees must be planted from a grafted or cutting. Legend has it that every one of navel orange trees originates from a single mutant tree grown-up in the 1820s in Brazil.

\section{Historical names}

Some consider that the "golden apple" given to Hera, she married Zeus in Greek was actually an orange. The fruit classification "hesperidium" from "Hesperides" the nomenclature of the garden, Hera planted the seeds.

The English color term "orange" originate from the Arabic name for the medicinal plant, itself originate from the Tamil term "orang" meaning 6 and 5 (entail the 11 segment of the fruit).

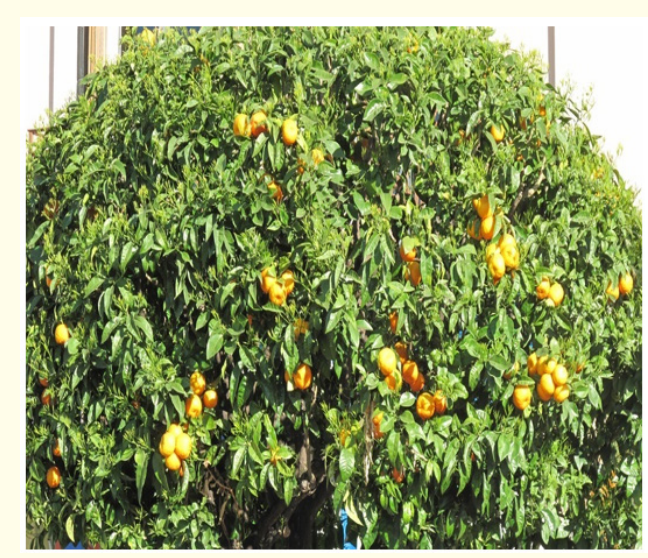

Figure B
Ayurvedic properties

- Appetizer

- Cardio stimulant

- Antiemetic property

- Anti diarrhoeal property improves digestion.

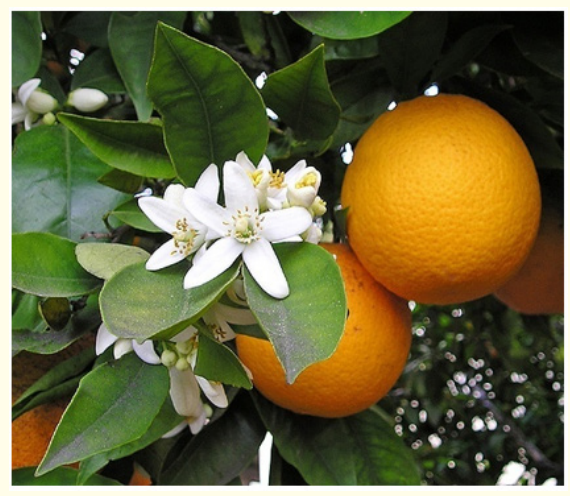

Figure C

\section{Phytochemistry}

'Phyto' is the Greek word for plant. There are many families of phytochemicals and they help the human body in a variety of ways. Phytochemicals may protect human from a host of diseases. Phytochemicals are non-nutritive plant chemicals that have protective effects and disease preventive properties.

Peel of Citrus aurantium contains terpenes such as carveol, carvone, menthol, perillylalcohol and perillaldehyde. Also contains vitamin-c, folic acid, potassium and pectin.

\section{Citrus aurantium peel extract}

- Extract orange oil in a jar by addition of alcohol. It will not dilute the orange scent in the finished oil.

- Essential oil in oranges, limonene is largely found in the peel. For better results, avoid cutting off any of the pith.

- Place them on a paper towel and leave them in direct sunlight until they are completely dry.

- Depending upon the humidity it takes couple of days. To accelerate the process, try chopping the orange peels into small pieces.

- After the peels have dried, place them in a food processor. Grind them until they are a coarse consistency.

- Fill a bowl with warm tap water. It should be warm but not overly hot. Place the bottle of grain alcohol in the warm water and let it soak for about 20 minutes.

- Cover the peels with warm grain alcohol and give them a shake. More oil will get from the mixture. 
- Strain the mixture into a shallow dish; squeeze the liquid into the bowl. Cover the bowl with a cloth (or) paper towel. This will allow the remaining alcohol in the mixture to evaporate. Once it evaporate suck up the oil.

\section{Composition of orange peel}

The composition of the volatile oils is significantly different in flowers, leaves and peel.

- Linalyl acetate (50\%)

- $\quad$ Linalool (35\%)

- Limonene

- $\quad$ Folic acid.

\section{Constituents of orange peel}

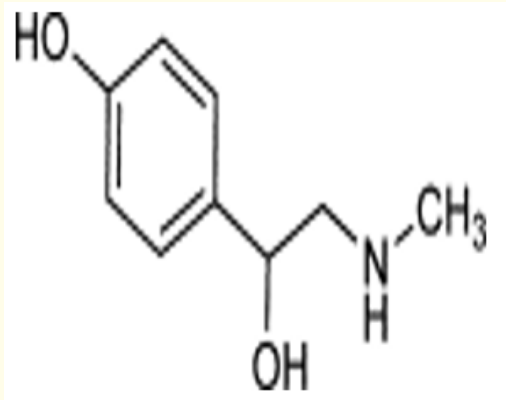

\section{4-[1-hydroxy-2-(methyl amino) ethyl] phenol}

Figure 1: Chemical structure of synephrine.

- d-limonene

- Hesperidin

- Naringin

- Auraptene

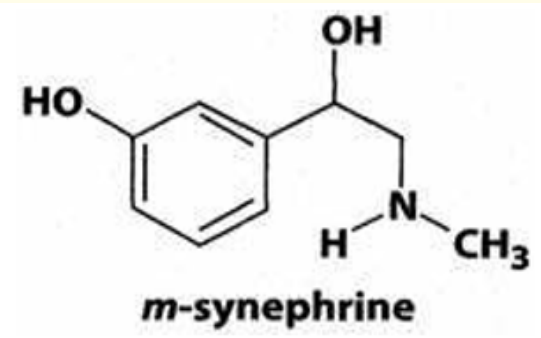

Figure 2: Chemical structure of synephrine.

\section{Medicinal uses}

- It stimulates central nervous system, lowers blood pressure and has sedative, analgesic, anti-inflammatory, antispasmodic, carminative, digestive, and diuretic effects.

- Used to treat Intestinal disorders (such as cramps, constipation, colic and diarrhoea).

- Respiratory disorders (such as cough, cold, bronchitis and tuberculosis).

- Obesity.

- Menstrual disorder.

- $\quad$ Cardiovascular disease (angina, hypertension).

- Anxiety.

- Depression.

- $\quad$ Stress.

\section{Pharmacological properties}

Laxative

Decoction of mixture of rheum species, Mangolia officinalis and Citrus aurantium screened for laxative effect in China [1] It is active, Effects are described from a multi-component prescription.

\section{Antiulcer activity}

Aqueous extract of plant screened for antiulcer activity in rat and found inactive against $\mathrm{Hcl} /$ Ethanol induced gastric ulcers at $500 \mathrm{mg} / \mathrm{kg}$ dose.

\section{Neuraminidase inhibition activity}

Methanol extract of whole plant screened for neuraminidase inhibition activity and found active at $1 \mathrm{ppm}$ concentration.

\section{Antifungal activity}

Essential oil screened in Paraguay for antifungal activity (plant pathogens) by agar plate method. It is active against Polyporus versicolor, Lentinus lepideus and Lenzites trabea. Essential oil screened in Egypt for antifungal activity in agar plate method and found inactive against Trichoderma viride, P. cyclopium.

\section{Antibacterial activity}

Essential oil screened for antibacterial activity in Egypt by agar plate method and found active against $S$. aureus, P. aeruginosa and inactive against E. coli, B. aureus. Essential oil screened in Thailand for antibacterial activity in agar plate method and found that active against $S$. pyogenes and $S$. aureus. 


\section{Antiyeast activity}

Commercial sample of essential oil screened in Australia for antiyeast activity in agar plate method $0.25 \%$ found active against $C$. albicans.

\section{Smooth muscle relaxant activity}

Essential oil of plant screened for smooth muscle relaxant activity and found active in guinea pig trachea at ED50 $64 \mathrm{mg} /$ liter dose and also found inactive in guinea pig ileum at $100 \mathrm{mg} /$ liter. Insect Repellent Activity Essential oil screened in India for insect repellent activity in Apis florea. It is active in $0.0125 \%$ by Olfactometer test.

\section{Antiulcer activity}

Essential oil screened for glutathione-S-transferase induction in mouse liver. Dose of $30 \mathrm{mg} /$ animal given by intragastric route every 2 days for total of 3 doses is inactive in ulcer in liver, stomach and small intestine [2]. Anti-tumour activity essential oil screened for tumour promotion inhibition in rat. Dose $1 \%$ of diet is active in CA-mammary-DMBA. Essential oil of plant screened for Glutathione-S transferase induction activity in mouse stomach, small intestine, liver by intragastric route at dose $30 \mathrm{mg} / \mathrm{animal}$ and find inactive. Dose was given every 2 days for a total of 3 doses.

\section{Anticarcinogenic properties}

In the tumour microenvironment, from cancer cells initiation to promotion and eventually progression, compelling evidence indicates the potential activities of flavonoids in Citrus peel cover inhibiting oncogenesis, proliferation, neovascularization, and metastasis and inducing apoptosis. Figure 1 schematizes the main anticarcinogenic pathways of Citrus peels flavonoids and different bioactivity aspects of specific compound.

Citrus peel flavonoids substantially influence on cell cycle arrest. Cell cycle is an important regulatory mechanism of cell growth, development and differentiation. In mammals, the cell cycle comprises the G1, S, G2, and M phases. The cell cycle progression depends on a cascade of enzymes by sequential activation and in activation of cyclin, cyclin-dependent kinases (CDKs) and cyclin-dependent kinases inhibitors (CDKIs).

\section{Antimicrobial activity}

Oil of dried seed screened for antibacterial, antifungal, antiyeast activity by agar plate method $(10 \mathrm{mg} / \mathrm{ml})$ and found inactive against S. viridans, Diplococcus pneumoniae, C. diphtheriae, S. aureus, Streptococcus pyogenes, Piedraia hortae, Microsporum canis,
Microsporus gypseum, Trichophyton mentagrophytes, Phialophora jeanselmei, Candida albicans, Candida tropicalis and also screened for antihelmintic activity and found inactive against Antihelmintic parasite.

\section{Materials and Methods \\ Collection of plat material}

The fully ripen Citrus aurantium fruits were collected from the nearby market and was authenticated by Dr. K. Madhav Chetty, Dept. of Botany Asst. Professor, SVU, Tirupathi, India. Citrus aurantium fruits were first washed, peeled, made into small slices and kept for shade drying. The dried peels were powdered and used for formulation purpose.

\section{Experimental animals}

Male Wistar rats and mice weighing (180 - 220g) (20 - 30g) were providing by means of animal house of. They were housed in rooms of ventilated at a temp of $24 \pm 2^{\circ} \mathrm{C}$ along with a $12 \mathrm{~h}$ light or dark cycle and $54 \pm 5 \% \mathrm{RH}$, fed on standard pellet and water ad libitum all the way through the experimental phase. The animals were habituated for a phase of 1 week. The experiments were carrying out by following the guidelines of the CPCSEA, committee for the purpose of control and supervision of experiments on animals. New Delhi, India and permitted by means of the IAEC, Institutional Animal Ethical Committee of Sigma Institute of Clinical Research and administration pvt. Ltd Hyderabad.

\section{Determination of acute oral toxicity}

Study of Acute toxicity was executed according to method of acute toxic class, category IV substance of OECD 423 guidelines. Albino rats $(n=3)$ of both sex chosen by means of technique of random sampling were employed in this exploration. The animals were kept up for starving $4 \mathrm{hrs}$ with free admittance to water simply. The plant extract of Peel of Orange were treating by oral method with utmost dose of $2 \mathrm{~g} / \mathrm{kg}$ b.w. The death was seen within 3 days. If death was observable in $2 / 3$ or $3 / 3$ of rat animals, subsequently the dose treating is considered like a dose of toxic. Nevertheless, if the death was seen barely 1 rat out of 3 animals then the identical dose was repetitive once more to validate the toxic effect. If death was not seen, the process was then repetitive with superior dose.

\section{Anti-platelet aggregation effectiveness}

The technique of Mekhfi., et al. (2004), Mekhfi., et al. (2006) effects of extracts and tannins from Arbutus unedo leaves on rat platelet aggregation) [3] was utilized with a few modifications. The 
anti-platelet aggregation effectiveness of the extract was discretely tested on ADP (5 mM), thrombin $(5 \mathrm{U} / \mathrm{ml})$, and epinephrine (10 $\mathrm{mM})$ induced platelet aggregation. The platelets $(100 \mu \mathrm{l})$ were incubated for 5 min with diverse concentrations of the crude extract $(1,3$ and $10 \mathrm{mg} / \mathrm{ml})$ and an aggregation inducer $(20 \mu \mathrm{l})$ was added to the mixtures. Aggregation was measured with the Biotek plate reader utilizing Gen5 software by means of following alters in absorbance at $415 \mathrm{~nm}$. DMSO (1\%) was used as negative control and heparin was employed as positive control.

\section{In-vitro}

All extracts will be evaluated for in-vitro and in-vivo anticoagulant activity. Several in-vitro models have been developed to study anticoagulant activity. In the present study all the extracts will be subjected to the following Anticoagulant models to evaluate the extract possessing maximum activity.

The blood samples will be placed separately in containers containing tri-sodium citrate to prevent the clotting process. Centrifugation (15 minutes at the rate $3000 \mathrm{rpm}$ ) will be carried out to separate the blood cells from plasma in order to obtain pure platelet plasma (ppp) for prothrombin time test. The obtained plasma sample is poured separately in plane containers using automatic pipette and stored at room temperature. $0.2 \mathrm{ml}$ plasma, $0.1 \mathrm{ml}$ of crude extracts of varying concentrations and volume of $\mathrm{CaCl}_{2}(25$ $\mathrm{mM}$ ) will be added together in a clean fusion tube and incubated at $37^{\circ} \mathrm{C}$ in water bath. Control will be prepared where, extract solutions is replaced by same volume of $0.9 \%$ saline water. The clotting time will be recorded with stopwatch by tilting the test tubes every 5 seconds. This time is called the prothrombin time [4].

\section{In vitro anti-platelet aggregation study}

The extract was discretely dissolved in 1\% DMSO for utilization in the anti-platelet aggregation investigation [5].

\section{In-vivo in rats}

Group 1: The rats in this group served as Control. They were administered with $0.4 \mathrm{ml}$ of distilled water or $10 \mathrm{mg} / \mathrm{kg}$ saline.

Group 2: The rats in this group were treated with standard feed, water and $50 \mathrm{mg} / \mathrm{kg}$ of the extract.

Group 3: The rats in this group were treated with standard feed, water and $100 \mathrm{mg} / \mathrm{kg}$ of the extract.

Group 4: The rats in this group were treated with standard feed, water and $200 \mathrm{mg} / \mathrm{kg}$ of the extract.

\section{Sample collection and analysis}

Blood samples were collected from the rats by ocular vein puncture under anaesthesia of chloroform [6]. The samples were added into EDTA and sodium chloride bottles for haemorheological and haematological tests respectively [7]. Samples were analyzed within 6 hours of collection employing standard methods [8].

\section{In-vivo in mice}

The test samples were dissolved in $2 \%$ tween 80 and given i.v. into tail veins under a mild anesthesia by means of ether: (i) 4 groups of mice received extract solution of orange peel at the doses of 0 (saline), 1.1, 3.3 and $10 \mathrm{mg} / \mathrm{kg}$, one hour later, blood was collected; (ii) 3 groups of mice received extract solution of orange peel or heparin at a dose of $10 \mathrm{mg} / \mathrm{kg}$ or saline, and subsequently blood was collected at $0.5,1,2$ and $3 \mathrm{~h}$ following administration of the test or vehicle agents [9].

\section{Statistical analysis}

All data were expressed or represented as the Avg \pm SD. For statistical analysis of the obtained data, group means were compared by means of one-way analysis of variance (ANOVA) followed by means of Dunnett's test, $\mathrm{P}<0.05$ was measured as significant.

\section{Results and Discussion}

Preliminary phytochemical screening: Outcome of the preliminary phytochemical assessment on $80 \%$ Ethanolic extract of peel of Orange (80\% EOP) are shown in table 1.

\begin{tabular}{|l|c|}
\hline Phytochemical constituents & $\mathbf{8 0 \%}$ Ethanolic extract \\
\hline Alkaloids & +++ \\
\hline Glycosides & ++ \\
\hline Carbohydrates & + \\
\hline Flavonoids & +++ \\
\hline Saponins & +++ \\
\hline Tannins & ++ \\
\hline Steroids & +++ \\
\hline Proteins and Amino acids & - \\
\hline Phytosterols & ++ \\
\hline Phenols & +++ \\
\hline Triterpenoids & +++ \\
\hline
\end{tabular}

Table 1: Preliminary phytochemical assessment of $80 \%$ EOP. 
$\%$ yield of crude extract of peel of orange

\begin{tabular}{|c|c|c|c|}
\hline Sl. No. & Solvent & $\begin{array}{c}\text { Colour and Consis- } \\
\text { tency }\end{array}$ & $\begin{array}{c}\text { Percentage } \\
\text { yield }\end{array}$ \\
\hline 1 & Ethanol $80 \%$ & Brown sticky & $8.2 \%$ \\
\hline
\end{tabular}

Table 2
Acute oral toxicity of $80 \%$ EOP

The medicinal plant extract of orange peel didn't exposed any mortality and toxicity.

Even at uppermost dose of $2 \mathrm{~g} / \mathrm{kg}$ b.w. employed.

Sheet of toxicity record: Sheet of Toxicity record is as follows.

\begin{tabular}{|c|c|c|c|c|c|c|c|c|c|c|c|c|c|c|}
\hline \multirow{2}{*}{ S.no. } & \multirow{2}{*}{ Code } & \multicolumn{2}{|c|}{ Toxicity } & \multirow{2}{*}{$\begin{array}{c}\text { Time of } \\
\text { Death }\end{array}$} & \multicolumn{10}{|c|}{ Observation } \\
\hline & & Onset & Stop & & Skin colour & Eyes & Resp & CNS & Tre & Con & Sali & Diah & Sleep & Leth \\
\hline 1. & EOP & $\mathrm{X}$ & $\mathrm{X}$ & $\mathrm{X}$ & $\mathrm{X}$ & $\mathrm{X}$ & $\mathrm{x}$ & $\mathrm{x}$ & $x$ & $x$ & $\mathrm{x}$ & $\mathrm{x}$ & $\mathrm{X}$ & $\mathrm{X}$ \\
\hline
\end{tabular}

Table 3: (TRE-Tremor, CON-Convulsions, SALI- Salivation, Diah - Diarrhea, LET-Lethargy). $\times=$ Negative $\varnothing=$ Positive.

\section{Anti-platelet aggregation effectiveness}

The potential capability of the peel extract to prevent aggregation of platelet was subsequently investigated on platelets of rat. The anti-platelet aggregation effectiveness of the extract was discretely tested on thrombin, epinephrine or ADP induced platelet aggregation of rat.

Inhibitory effectiveness (\%) of the extract of Orange Peel on aggregation of platelet.

Thrombin, heparin, ADP and epinephrine-induced aggregation of platelet.

\begin{tabular}{|l|c|c|c|}
\hline \multirow{2}{*}{ Extract } & \multicolumn{3}{|c|}{ Concentration (mg/ml) } \\
& 1 & 3 & 10 \\
\cline { 2 - 4 } & $78.2^{*} \pm 1.60$ & $81.3^{*} \pm 8.20$ & $82.0^{*} \pm 4.09$ \\
\hline Thrombin-E & $11.9 \pm 0.24$ & $22.1 \pm 0.09$ & $81.3^{*} \pm 1.01$ \\
\hline Heparin-T & $42.3 \pm 0.02$ & $79.4^{*} \pm 0.3$ & $66.9 \pm 1.15$ \\
\hline ADP-E & $45.8 \pm 0.12$ & $69.7^{*} \pm 0.79$ & $89.7^{*} \pm 0.18$ \\
\hline Epinephrine-E & & & \\
\hline
\end{tabular}

Table 4

A concentration rely inhibitory effectiveness on the aggregation induced by thrombin, ADP and epinephrine was observable for every one of concentration of the extract. The effectiveness of the extracts was superior to that of heparin $(1 \mathrm{mg} / \mathrm{ml})$, a marketable anticoagulant.

In vitro anticoagulant effectiveness of ethanolic extract of orange peel

The anticoagulant effectiveness of extract was executed on the whole blood of rat.

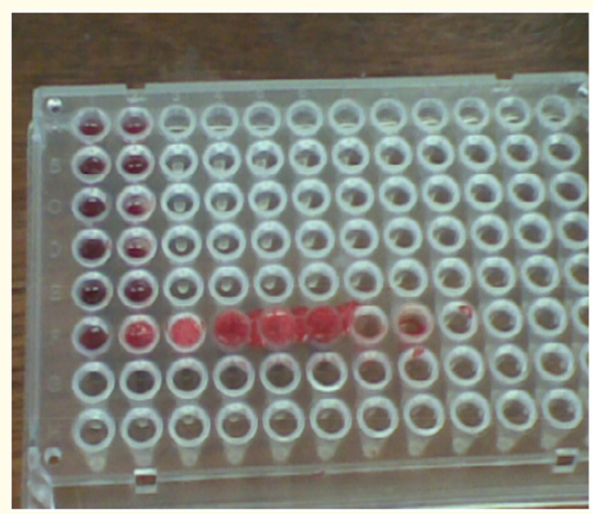

Figure 3: The anticoagulant effectiveness of EOP on the rat whole blood. The blood was added to A (1\% DMSO-blank); B (thrombin); C (ADP); D (epinephrine); E (arachidonic acid); and F1-6 (compound at 1, 3 and $10 \mathrm{mg} / \mathrm{ml}$ ). The experiment was done in duplicates.

The test compound showed the anticoagulant effectiveness as it delayed blood clotting time in a concentration rely manner (more than 5 minutes, wells F3-6) contrast to the groups of control (wells A-E) were clotting took place within a minute.

\begin{tabular}{|l|c|c|l|}
\hline Parameters & Group 1 & Group 2 & P Value \\
\hline & Control & $\mathbf{5 0 ~} \mathbf{~} \mathbf{~} / \mathbf{k g}$ & \\
\hline PCV $(\%)$ & $37.10 \pm 1.02$ & $36.20 \pm 3.18$ & $\mathrm{p}>0.05$ \\
\hline ESR (mm/hr) & $2.20 \pm 0.58$ & $2.10 \pm 1.16$ & $\mathrm{p}>0.05$ \\
\hline RPV (m.pas) & $1.19 \pm 0.24$ & $1.19 \pm 0.10$ & $\mathrm{p}>0.05$ \\
\hline RWBV (m.pas) & $1.37 \pm 0.08$ & $1.22 \pm 0.10$ & $\mathrm{p}>0.05$ \\
\hline PFC (g/l) & $0.76 \pm 0.33$ & $0.78 \pm 0.17$ & $\mathrm{p}>0.05$ \\
\hline Hb (g/dl) & $13.12 \pm 2.07$ & $14.71 \pm 4.16$ & $\mathrm{p}>0.05$ \\
\hline WBC (x10 $/ \mathrm{l})$ & $3.93 \pm 0.63$ & $4.44 \pm 0.58$ & $\mathrm{p}>0.05$ \\
\hline PLT $\left(\mathrm{x} 10^{9} / \mathrm{l}\right)$ & $344050 \pm 23280$ & $285500 \pm 16250$ & $\mathrm{p}>0.05$ \\
\hline
\end{tabular}

Table 5: Haematological parameters $-50 \mathrm{mg} / \mathrm{kg}$. 


\begin{tabular}{|l|c|c|c|}
\hline Parameters & Group 1 & Group 2 & P Value \\
\hline & Control & $\mathbf{1 0 0} \mathbf{~ m g} / \mathbf{k g}$ & \\
\hline PCV $(\%)$ & $37.10 \pm 1.02$ & $35.06 \pm 3.21$ & $\mathrm{p}>0.05$ \\
\hline ESR (mm/hr) & $2.20 \pm 0.58$ & $2.08 \pm 1.12$ & $\mathrm{p}>0.05$ \\
\hline RPV (m.pas) & $1.19 \pm 0.24$ & $1.06 \pm 0.11$ & $\mathrm{p}>0.05$ \\
\hline RWBV (m.pas) & $1.37 \pm 0.08$ & $1.27 \pm 0.09$ & $\mathrm{p}>0.05$ \\
\hline PFC (g/l) & $0.76 \pm 0.33$ & $0.88 \pm 0.16$ & $\mathrm{p}>0.05$ \\
\hline Hb (g/dl) & $13.12 \pm 2.07$ & $11.05 \pm 4.18$ & $\mathrm{P}<0.05$ \\
\hline WBC (x10 $/ \mathrm{l})$ & $3.93 \pm 0.63$ & $3.71 \pm 0.57$ & $\mathrm{p}>0.05$ \\
\hline PLT $\left(\mathrm{x} 10^{9} / \mathrm{l}\right)$ & $344050 \pm 23280$ & $273080 \pm 16450$ & $\mathrm{P}<0.05$ \\
\hline
\end{tabular}

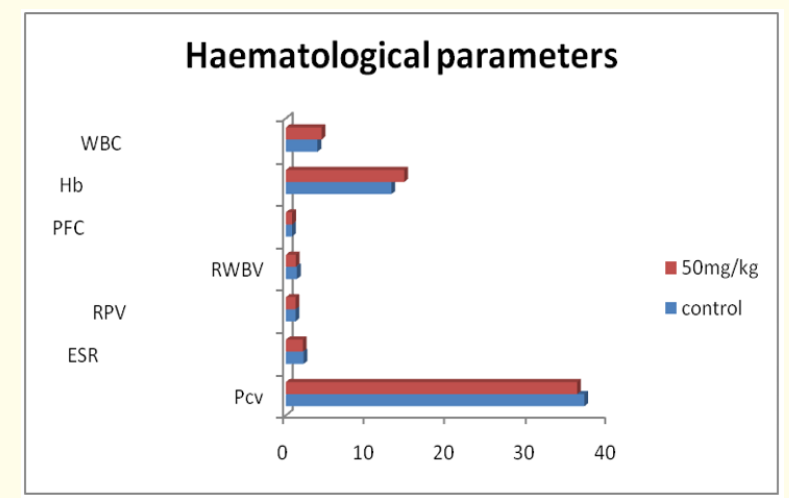

Table 6: Haematological parameters $-100 \mathrm{mg} / \mathrm{kg}$.

\begin{tabular}{|l|c|c|c|}
\hline Parameters & Group 1 & Group 2 & P Value \\
\hline & Control & $\mathbf{2 0 0} \mathbf{~ m g} / \mathbf{k g}$ & \\
\hline PCV (\%) & $37.10 \pm 1.02$ & $36.05 \pm 3.09$ & $\mathrm{p}>0.05$ \\
\hline ESR (mm/hr) & $2.20 \pm 0.58$ & $2.06 \pm 1.18$ & $\mathrm{p}>0.05$ \\
\hline RPV (m.pas) & $1.19 \pm 0.24$ & $1.18 \pm 0.07$ & $\mathrm{p}>0.05$ \\
\hline RWBV (m.pas) & $1.37 \pm 0.08$ & $1.37 \pm 0.13$ & $\mathrm{p}>0.05$ \\
\hline PFC (g/l) & $0.76 \pm 0.33$ & $0.83 \pm 0.19$ & $\mathrm{p}>0.05$ \\
\hline Hb (g/dl) & $13.12 \pm 2.07$ & $17.92 \pm 4.18$ & $\mathrm{P}<0.05$ \\
\hline WBC (x10 $/ \mathrm{l})$ & $3.93 \pm 0.63$ & $5.33 \pm 0.59$ & $\mathrm{p}>0.05$ \\
\hline PLT $\left(\mathrm{x} 10^{9} / \mathrm{l}\right)$ & $344050 \pm 23280$ & $275080 \pm 16350$ & $\mathrm{P}<0.05$ \\
\hline
\end{tabular}

Table 7: Haematological parameters-200 mg/kg.

\begin{tabular}{|l|c|c|c|c|c|}
\hline \multirow{2}{*}{ Sample } & $\begin{array}{c}\text { Dose } \\
\text { (mg/ } \\
\text { kg) }\end{array}$ & $\begin{array}{c}\text { Injection time of } \\
\text { thrombin After } \\
\text { treatment of drugs }\end{array}$ & $\begin{array}{c}\text { No. } \\
\text { of } \\
\text { mice }\end{array}$ & $\begin{array}{c}\text { Sur- } \\
\text { vival }\end{array}$ & $\begin{array}{c}\text { Surviv- } \\
\text { al rate } \\
\text { (\%) }\end{array}$ \\
\hline Saline & 5 & $10 \mathrm{~min}$ & 10 & 0 & 0 \\
\hline \multirow{3}{*}{ Heparin } & 5 & $10 \mathrm{~min}$ & 10 & 10 & 100 \\
\cline { 2 - 6 } & 5 & $3 \mathrm{hr} 30 \mathrm{~min}$ & 10 & 0 & 0 \\
\cline { 2 - 6 } & 20 & $5 \mathrm{hr}$ & 10 & 0 & 0 \\
\hline \multirow{3}{*}{$\begin{array}{l}\text { Orange } \\
\text { peel }\end{array}$} & 20 & $10 \mathrm{~min}$ & 10 & 4 & 40 \\
\cline { 2 - 6 } & & $3 \mathrm{hr} 30 \mathrm{~min}$ & 10 & 7 & 70 \\
\cline { 2 - 6 } & & $5 \mathrm{hr}$ & 10 & 9 & 90 \\
\hline
\end{tabular}

Table 8: Thrombin induced lethality in mice.

\begin{tabular}{|l|c|c|c|}
\hline Control & T1 -1.1 & T2-3.3 & T3-10 \\
\hline $25 \pm 1.06$ & $30 \pm 1.09$ & $41 \pm 2.26$ & $58 \pm 0.98$ \\
\hline
\end{tabular}

Table 9: Clotting time for various doses of extract.
Figure 4: Histogram showing haematological parameters$50 \mathrm{mg} / \mathrm{kg}$.

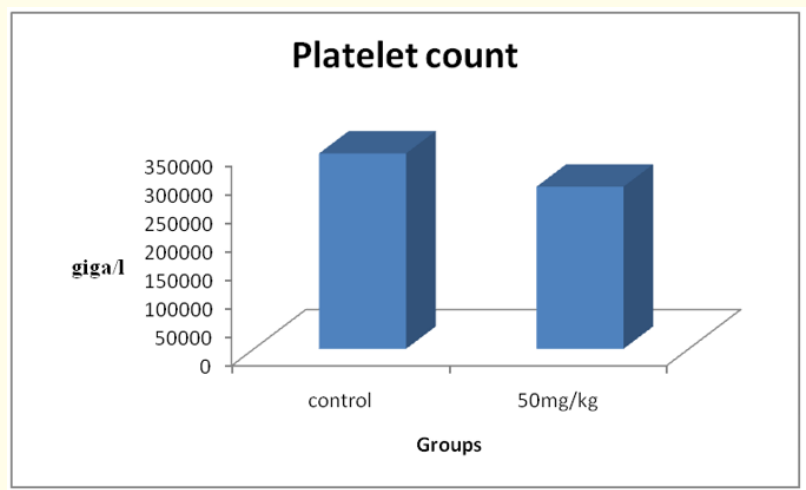

Figure 5: Histogram showing platelet count-50 mg/kg.

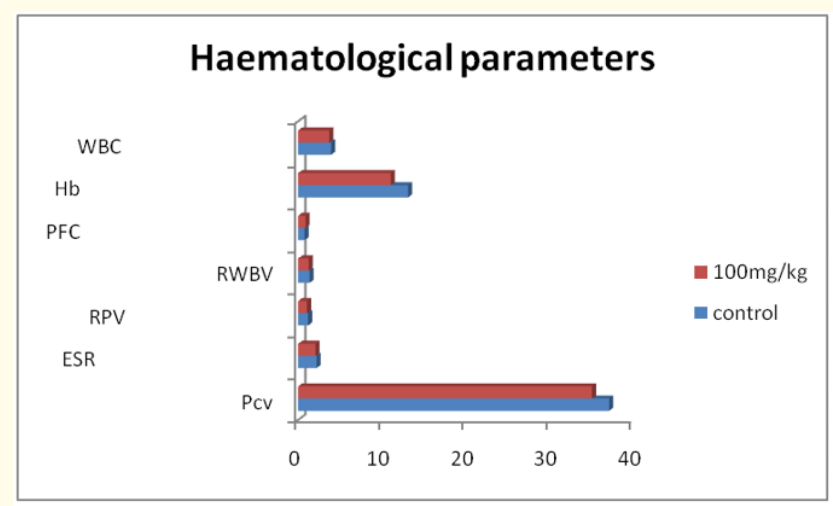

Figure 6: Histogram showing haematological parameters-100 $\mathrm{mg} / \mathrm{kg}$. 


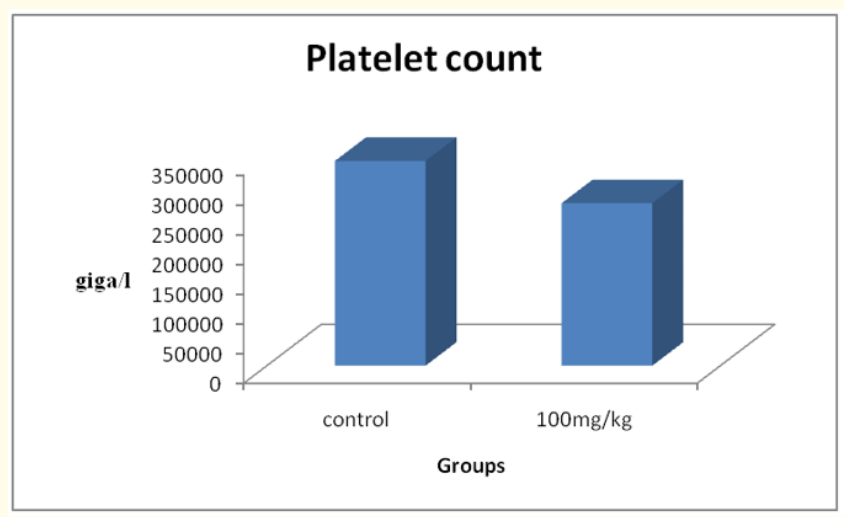

Figure 7: Histogram showing platelet count-100 mg/kg.

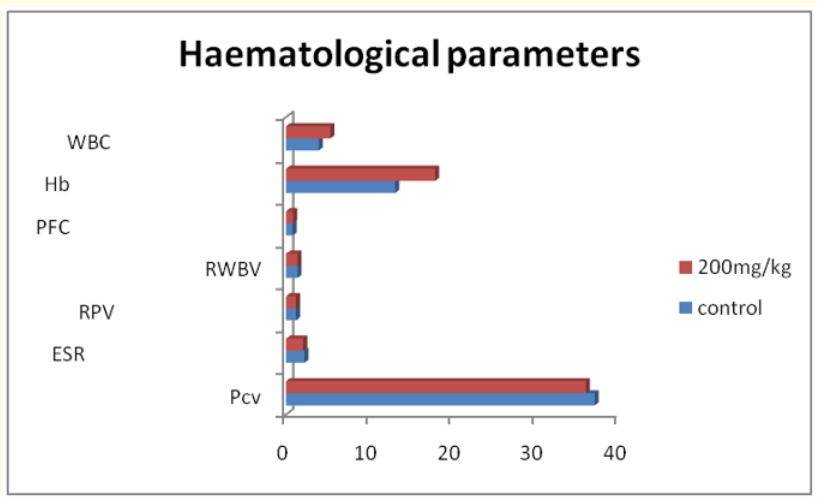

Figure 8: Histogram showing haematological parameters-200 $\mathrm{mg} / \mathrm{kg}$.

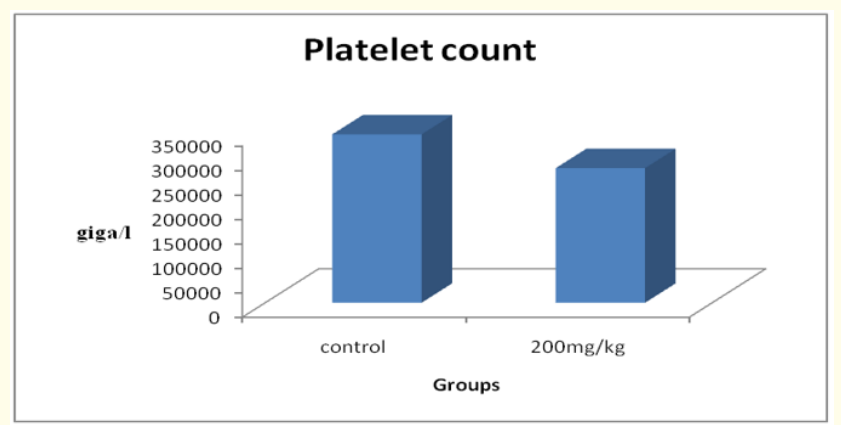

Figure 9: Histogram showing platelet count-200 mg/kg.

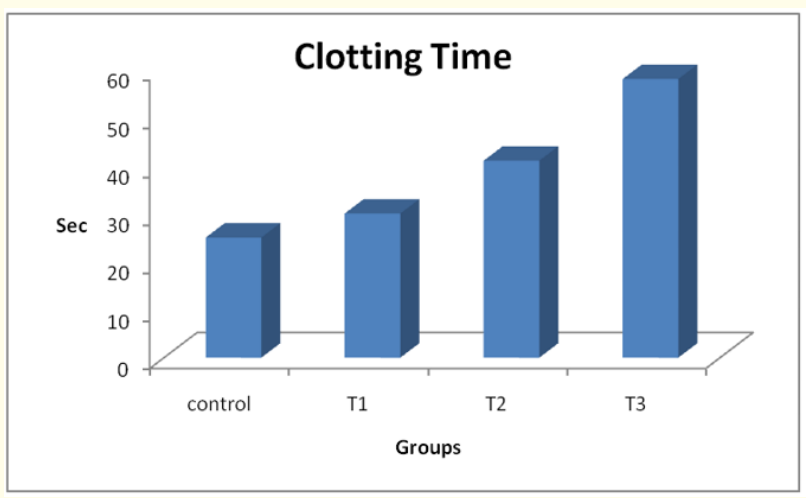

Figure 10: Histogram showing clotting time at various doses.

\section{Discussion}

Clotting of blood is a common and necessary procedure that needs to be cautiously regulated. Aggregation of Platelet is the chief event in the cascade of clotting of blood under both pathophysiological and physiological circumstances. Whilst clotting may perhaps advantageous in prevent bleeding, unchecked internal generation of blood clots may perhaps fatal. Platelets dysfunctions considerably responsible for pathogenesis of CVD [10]. Different treatments are made accessible to put off irregular activation and aggregation of platelets. Nevertheless, in spite of their presence of a therothrombotic diseases persist to pose a risk to health of human.

The results acquired from this exploration advocate that the medicinal plant, Orange peel, possesses the capability to inhibit the aggregation of platelets: The extract of the plant peel inhibited the effect of thrombin on the artificial substrate (i.e. chromogenix), and subsequent too inhibited rat aggregation of platelets provoked with ADP, thrombin, and epinephrine. It is notable that the inhibition of aggregation of Platelet was adjunct by means of the inhibition of lipid peroxidation, a course that is allied with clotting of blood Basic aggregation properties of washed rat platelets: Correlation between aggregation, phospholipid degradation malondialdehyde, and thromboxane formation [11]. Lessening in formation of MDA advocates the potential of the extract to inhibit phospholipid degradation, thromboxane and cyclooxygenase synthase; this is too attributing of non-steroidal anti-inflammatory agents [12]. 
The extent to where the extract inhibited the aggregation of the enzyme treat platelets does advocate that the extracts may perhaps not merely be inhibiting thrombin and the other platelet agonists but may perhaps too be preventing aggregation of degraded platelets. Yet, the platelets loss of sensitivity to the agonists cannot be ruled out. The prior incubation of platelets by the proteolytic enzymes has earlier been described to diminish platelet sensitivity to the agonists [13].

The anti-aggregation of Platelet effectiveness was seen mostly in the extract of the semi-polar solvent extract highest dose indicating the highest effect. The results point out that the most active antiaggregation of Platelet constituent in the plant extract may perhaps non-polar in nature. Familiarity of phytochemical composition of plant under exploration is imperative in considerate its biological or medicinal actions. The higher anti aggregation of Platelet effect of extract could partially be accredited to their high flavonoid and phenolic content. A variety of researchers have described the advantageous effects of these test compounds on platelet functions. The flavonoid separated from Urtica dioica inhibited thrombin, epinephrine, ADP and collagen provoked aggregation of Platelet [14]. Nevertheless, the synergistic effects of the other constituents cannot be ruled out, because alkaloids too contain anti-aggregation of Platelet effect [14].

The capability of the extract to inhibit the arachidonic acid provoked aggregation of Platelet signify its potential to be developed into an excellent pharmacological anti-platelet and anti-inflammatory medicament. Arachidonic acid provoked aggregation of Platelet is mediated by means of prostaglandin $\mathrm{H} 2$ and thromboxane $\mathrm{A} 2$ [16]. Consequently, the prostaglandin $\mathrm{H} 2$ is too a forerunner for the prothrombotic thromboxane A2. The effectiveness of the extract to put off clotting of blood is further evident by means of its capability to noticeably delay the in vitro clotting time of the whole blood of rat.

Plants of Medicinal value are undoubtedly wealthy sources of biologically active ingredients vital to health of human. In case utilized appropriately medicinal plants are a key to a large range of diseases together with atherothrombotic diseases. The outcome of this work scientifically certifies the traditional apply of EOP in the managing of clotting of blood allied diseases. Bearing in mind the escalating demand on the discovery and development of novel pharmacologically active medicaments to substitute the at present utilized anti-aggregation of Platelet medicaments, the outcome reported in this thesis advocate the potential application of these constituent in the managing of clotting of blood allied diseases.

It is reported that the half-life of heparin is reliant on the dose. In the current exploration, we investigated the effectiveness of heparin at doses of $5 \mathrm{mg} / \mathrm{kg}$ and $20 \mathrm{mg} / \mathrm{kg}$ in mice, correspondingly. To verify the long-lasting efficacy of extract, we too explored the antithrombotic effect utilizing a thrombin-provoked lethality method in mice. We contrast the protection of lethality by means of heparin and extract on this experimental model. The outcomes demonstrate that the pre-treatment of EOP $(20 \mathrm{mg} / \mathrm{kg}$ ) reasonably protected in opposition to lethality by means of $40 \%$ as it was given at 10 min prior to injection of thrombin. Astonishingly, EOP could protect against lethality by means of $70-90 \%$ as it was treated at 3.5 and $5 \mathrm{~h}$ prior to a thrombin challenge. Heparin, though, could noticeably protect against lethality as treated 10 minutes prior to challenge by means of thrombin.

As the 2 groups (control and $50 \mathrm{mg} / \mathrm{kg}$ EOP) were compared, there was no significant variation in both the haematological and haemorheological parameters explored. This is a sign that at concentration of $50 \mathrm{mg} / \mathrm{kg}$ the extract is well tolerated and therefore no alter were recorded. At concentration of $100 \mathrm{mg} / \mathrm{kg}$, the packed cell volume (PCV) was abridged (though not statistically significant) whilst the haemoglobin concentration was too abridged was statistically noteworthy. The count of platelet illustrated statistically significant lessening. At $100 \mathrm{mg} / \mathrm{kg}$ the extract displayed anti-platelet effect. Fascinatingly, at $200 \mathrm{mg} / \mathrm{kg}$ the haemoglobin concentration was augmented. This almost certainly justifies its implication in the treatment of anaemia. The extract too displayed anti-platelet effect at this concentration.

Outcome from the phytochemical assessment of extract of orange peel exposed the existence of

1. Saponins,

2. Alkaloids,

3. Terpenoids,

4. Tannins,

5. Phenols,

6. Flavonoids and

7. Glycosides as the promising biologically active principles, been separated from the other medicinal plants too and originated to have anticoagulant effectiveness. 
In nutshell, the extract of orange peel extract possesses considerable anticoagulant effectiveness.

\section{Conclusion}

From all the result found during evaluation of in-vitro and in-vivo anticoagulant activity of orange peel extract of Citrus aurantium, dose dependent anticoagulant activity may mainly exhibit anticoagulant activity correlating with the intrinsic coagulation process.

Further work has to been done for isolation of active phytochemical constituents from the peel.

\section{Acknowledgement}

Authors are sincerely thankful to Sri Padmavathi Mahila viswavidyalayam, Tirupathi for providing necessary facilities for carry out research work.

\section{Bibliography}

1. Nielson F., et al. "Plasma malondialdehyde as a biomarker for oxidative stress: Reference interval and effects of life-style factors". Clinical Chemistry 43.7 (1997): 1209-1214.

2. Gadi D., et al. "Parsley extract inhibits in vitro and ex vivo platelet aggregation and prolongs bleeding time in rats". Journal of Ethnopharmacology (2009): 125.

3. Mekhfi M., et al. "An effect of extracts and tannins from Arbutus unedo leaves on rat platelet aggregation". Phytotherapy Research 20 (2006): 1350E139.

4. Ambrosio G., et al. "Reactive oxygen metabolites and arterial thrombosis (Review)". Cardiovascular Research 34 (1997): 445-452.

5. Park BS Son., et al. "Antiplatelet effects of acid amides isolated from the fruits of Piper longum L". Phytomedicine 14.12 (2007): 853-855.

6. M Cheesbrough. "Haematological tests: in District laboratory practice in tropical countries". (London: Cambridge University Press (2000) 297.

7. HL Reid and AC Ugwu. "A simple technique for rapid determination of plasma viscosity". Nigerian Journal of Physiological Sciences 3 (1987): 45-48.

8. GC Ingram GC. "A suggested schedule for rapid investigation of acute haemostatic failure". Journal of Clinical Pathology 14 (1961): 156-160.
9. DW Li., et al. "Long duration of anticoagulant activity and protective effects of acharan sulfate in vivo". Thrombosis Research 113.1 (2004): 67-73.

10. Dutta-Roy AK., et al. "Effect of tomato extract on human platelet aggregation In vitro". Platelets 12.4 (2001): 2180E227.

11. Tomita T., et al. "Basic aggregation properties of washed rat platelets: Correlation between aggregation, phospholipid degradation malondialdehyde, and thromboxane formation". Journal of Pharmacology Methods 10.1 (1983): 31-44.

12. Kosela S., et al. "Effects of diterpene acids on malondialdehyde generation during thrombin induced aggregation of rat platelets". Archives of Pharmacal Research 9.5 (1986): 189-191.

13. Vellini M., et al. "Possible involvement of eicosanoids in the pharmacological action of bromelain". Arzneimittelforrschung 36.1 (1986): 110-112.

14. El Haouari., et al. "Inhibition of rat platelet aggregation by Urtica dioica leaves extracts". Phytotherapy Research 20 (2006): 568-572.

15. Chang ZQ., et al. "The in vitro antiplatelet, antioxidant and cellular immunity activity of Phellinus gilvus fractional extracts". World Journal of Microbiology and Biotechnology 24.2 (2008): 181-187.

16. Parise LV., et al. "Arachidonic acid-induced platelet aggregation is mediated by a thromboxane A2/prostaglandin $\mathrm{H} 2$ receptor interaction". Journal of Pharmacology and Experimental Therapeutics 228.1 (1984): 240-244.

\section{Assets from publication with us}

- Prompt Acknowledgement after receiving the article

- Thorough Double blinded peer review

- Rapid Publication

- Issue of Publication Certificate

- High visibility of your Published work

Website: www.actascientific.com/

Submit Article: www.actascientific.com/submission.php Email us: editor@actascientific.com

Contact us: +919182824667 